\title{
Identifying Influencing Factors of Regional Agricultural Drought Vulnerability Based on PSR-TGRC Method
}

\author{
Dongxing Zhang $\mathbb{D}^{1}{ }^{1}$ Wenkai Cao, ${ }^{2}$ and Bing $Q \mathbf{i}^{1}$ \\ ${ }^{1}$ School of Management and Economics, North China University of Water Resources and Electric Power, Zhengzhou, China \\ ${ }^{2}$ School of Information and Management Sciences, Henan Agricultural University, Zhengzhou, China \\ Correspondence should be addressed to Dongxing Zhang; zhangdx_2019@163.com
}

Received 10 March 2021; Revised 2 June 2021; Accepted 5 July 2021; Published 19 July 2021

Academic Editor: Zenghui Wang

Copyright (c) 2021 Dongxing Zhang et al. This is an open access article distributed under the Creative Commons Attribution License, which permits unrestricted use, distribution, and reproduction in any medium, provided the original work is properly cited.

\begin{abstract}
Regional agricultural drought vulnerability (RADV) is a complex nonlinear problem caused by the interaction of multiple factors, and an objective and systematic method is proposed by this paper to identify its influencing factors, which plays an important role in preventing and regulating the risks of regional agricultural drought. Firstly, to provide a reference for the evaluation problem in selecting the number of factors, the influencing factors affecting RADV are revealed by using the method of phase space reconstruction (PSR). Secondly, to rank the importance of influencing factors, a grey trend relational analysis (TGRA) method is proposed, considering the dynamic development relationship between the RADV index and the influencing factors and integrating the absolute and relative variation of sequences in each corresponding period. Finally, to reduce the collinearity between the influencing factors, a grey trend relational clustering (TGRC) analysis method is proposed. According to the above steps, the process of identifying factors based on PSR-TGRC method is formed. Taking Henan Province as an example, 14 main influencing factors and their effects on RADV are identified from all 42 factors, and the identification results which are consistent with the actual drought relief work show the rationality and practicality of PSR-TGRC method and provide theoretical support for formulating strategies of regional agricultural disaster prevention and mitigation.
\end{abstract}

\section{Introduction}

With the acceleration of global warming and the intensity of human activities, the frequency and destructiveness of drought disasters (drought for short), which seriously threatens agricultural production, farmers' property security, and livelihood security, are gradually increasing and restricting the sustainable development of regional economy and society. Preventing and mitigating disasters has become a hot and wide concern issue in the international community and academia [1, 2]. The accumulation of RADV, which refers to the state of loss caused by the threat of drought in agricultural production [3], provides an intrinsic basis for the eventual outbreak of agricultural drought, and it is important to reduce drought losses and promote sustainable agricultural development by reducing RADV [4]. At present, the research on reducing the degree of RADV mainly focuses on the use of mathematical tools or intelligent algorithms to build vulnerability assessment models [5-8]. Scientific and reasonable influencing factors are the basis for obtaining accurate evaluation results. However, the requirements on the selection and quantity of factors are different [9-11], and there is no corresponding explanation and measurement standard for the selection of factors, which may directly affect the stability and accuracy of the evaluation of RADV. Therefore, it is necessary to make a reasonable and quantitative analysis for the factors affecting the RADV, determine the optimal number of factors affecting the evaluation of RADV, and identify the main influencing factors that need to be adjusted by intervening.

Obtaining the number of influencing factors accurately can effectively reduce the subjectivity of factors' selection in the evaluation problems. From the perspective of chaos theory, a method that quickly obtains the number of 
influencing factors by reconstructing the phase space of RADV index and calculating the correlation dimensions by $G-P$ algorithm $[12,13]$ was proposed. Chen and Gu obtained the number of factors affecting energy production and consumption by PSR [14]. Zhou researched the number of factors affecting the drought-affected area of Guangdong Province from 1950 to 1999 by PSR [15]. Xu et al. researched the number of factors affecting the total power of agricultural machinery in Heilongjiang Province by PSR [16]. In this paper, based on RADV index [17, 18], the number of factors affecting the evaluation of RADV is excavated by PSR, the subjectivity of factor selection is reduced, and the efficiency of data collection is improved.

The common identification methods of factors are the following: expert consultation and empirical knowledge [19], theoretical analysis [20], frequency analysis [21], network analysis [22], analytic hierarchy process [23], principal component analysis [24], and DEMATEL [25], and they have greatly promoted the scientificity and reliability of factors identification. However, in sudden natural disasters such as agricultural drought, there are often uncertainties such as inconsistent or incomplete data information as a result of different statistical paths. In addition, the formation mechanism of agricultural drought is complex and is influenced by many factors and coupled with human factors' interference; agricultural drought-related data often do not have a typical distribution law, so it is difficult to identify the RADV factors by using traditional theoretical analysis or statistical methods. Grey relational analysis and grey relational clustering analysis in Grey System theory do not require a large number of samples or the samples with statistical rules, so they are suitable for the identification of RADV factors [26].

Due to the obvious dynamic development characteristics between the influencing factors and the degree of RADV, to better measure the proximity level of the relative changes, the correlation between sequences is measured by the grey $T$-type relational analysis [27-29]. In this paper, with the full use of data information, the changing trend between data sequences is reflected from the absolute and relative amount of data changes, and a method of the grey trend relational analysis (TGRA) method is proposed, the same as the method of grey trend relational clustering (TGRC) analysis method, which is based on TGRA. Finally, the PSR-TGRC method is applied to the factor identification of RADV in Henan Province, and the managerial implications to reduce the RADV in Henan Province are proposed according to the identification results.

The main contributions of this paper are listed as follows:

(1) The influencing factors of RADV are quantitatively analyzed with the perspective of chaos theory, which provides a dimensional reference for the factors' selection in RADV assessment and reduces the subjectivity of threshold selection in relational clustering.

(2) Considering the absolute and relative amount of data changes, a grey relational analysis method based on trend of data changes is proposed, which measures the correlation degree comprehensively between RADV index and influencing factors, as well as the positive and negative correlation of development trends.

(3) Considering the perspectives of nature, economy, society, and so forth, a relatively comprehensive collection of RADV influencing factors has been constructed, and the main influencing factors in Henan Province and the influencing factors that need to be implemented urgently for intervention have been identified through the PSR-TGRC method, which will help in solving the agricultural drought warning in Henan Province.

The rest of this paper is organized as follows. Section 2 proposes the factor identification process based on PSRTGRC method. Section 3 applies the PSR-TGRC method to obtain the identification results of the influencing factors of RADV. Section 4 gives managerial implications according to the identification results. Section 5 gives the conclusions of this paper.

\section{Influencing Factors Identification Process Based on the PSR-TGRC Method}

In the process of factors identification, screening the main influencing factors and identifying their directions on the development trend of RADV are two key issues that need to be solved. Most of the factors are directly selected according to the relational threshold, but how to determine the threshold often lacks explanation, and the influence direction of factors on RADV lacks recognition.

Given the above problems, in Section 2.1, this paper puts forward the PSR method to reconstruct the RADV index, which quantifies the numbers of influencing factors, and provides a reference for the dynamic selection of relational clustering thresholds. In Section 2.2, firstly, this paper constructs a collection of influencing factors, and the TGRA method is proposed, which analyzes the correlation degree between the RADV index and the influencing factors, ranks the importance of the factors, and identifies the direction of the influencing factors on the development trend of RADV. Secondly, a TGRC method is proposed to analyze the collinearity between the influencing factors and reduce the redundancy between the factors. Finally, according to the number of main influencing factors, the ranking, and clustering results, the appropriate threshold is determined to identify the main influencing factors objectively and comprehensively. The methodology flow is shown in Figure 1.

\subsection{Determining the Number of Main Influencing Factors}

2.1.1. RADV Index. The RADV is a complex process of material and energy exchange with the outside world and it is influenced by natural conditions, technology, economy, policies, and other factors. The RADV index is a measure of RADV, which is based on the relationship between grain yield reduction and agricultural drought. The specific method is as follows. 


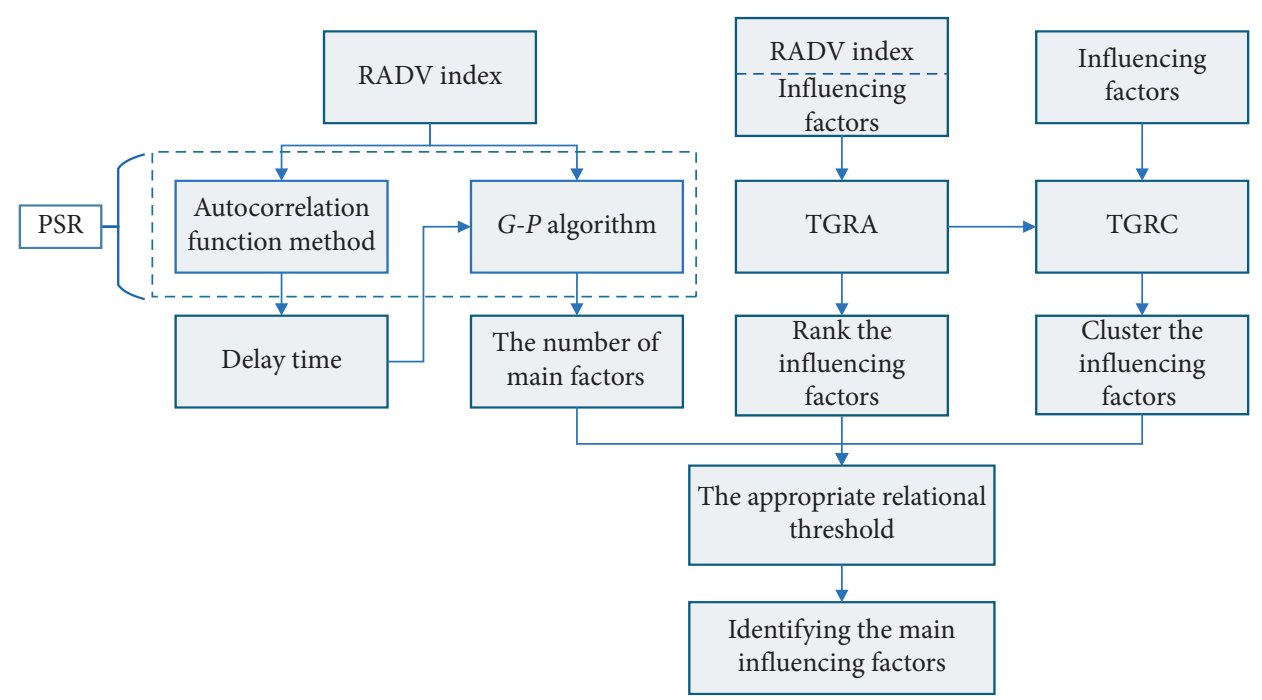

FIgURE 1: The methodology flow of this paper.

For each year of a region, the RADV index is obtained by using the crop under-receiving index for the current year divided by the corresponding drought index, and the formula is

$$
X_{0}=\frac{X_{0}^{\prime}}{X_{0}^{\prime \prime}}=\frac{(\widehat{H} / H)}{(\widehat{R} / R)}
$$

In formula (1), $X_{0}$ is the RADV index of a region, $X_{0}^{\prime}$ is the crop under-receiving index, $X_{0}^{\prime \prime}$ is the drought index of a region, and the crop under-receiving index $X_{0}^{\prime}$ is obtained by the expected output value $\hat{H}$ of a region divided by the actual output value in the current year. In order to eliminate the influence of technological progress and other factors on grain production, the autoregressive method in SPSS software is used to autoregress the data in time sequences at a time interval of 3 years, and then the expected value of grain production is obtained. Drought index $X_{0}^{\prime \prime}$ is obtained by using the regional multiyear average rainfall $\widehat{R}$ divided by the actual rainfall $R$ for the year.

2.1.2. PSR Method. By identifying the chaotic connotation of RADV index, the number of influencing factors affecting the RADV can be obtained by PSR method. The key of PSR method is to determine the delay time and the correlation dimensions [30]. In this section, the autocorrelation function method and $G-P$ algorithm are used to calculate the delay time $\tau$ and the correlation dimensions $D(m)$ of RADV index, respectively [31].

Definition 1. For RADV index $X_{0}=\left\{x_{0}\left(t_{1}\right), x_{0}\left(t_{2}\right), \ldots\right.$, $\left.x_{0}\left(t_{n}\right)\right\}$, the delay time is $\tau$, and the autocorrelation function is

$$
R(\tau)=\frac{E\left[\left(x_{0}\left(t_{a}\right)-\bar{X}_{0}\right)\left(x_{0}\left(t_{a}+\tau\right)-\bar{X}_{0}\right)\right]}{\sigma^{2}}
$$

In function (2), $t_{a}=t_{1}, t_{2}, \ldots, t_{n}-\tau, \bar{X}_{0}$ is the average of RADV index $X_{0}$, and $\sigma$ is the standard deviation of RADV index $X_{0}$.

Using SPSS data analysis software, the autocorrelation function value of RADV index $X_{0}$ is calculated, and the corresponding delay time $\tau$ is found when the autocorrelation function value first approaches zero.

The reconstructed phase space is $\mathbf{X}=\left(X_{1}, X_{2}, \ldots\right.$, $\left.X_{N}\right)^{\mathrm{T}}$, and each component in the space is $X_{b}=\left\{x\left(t_{b}\right)\right.$, $\left.x\left(t_{b}+\tau\right), \ldots, x\left(t_{b}+(m-1) \tau\right)\right\} ; \quad b=1,2, \ldots, N$, where $x\left(t_{b}\right)$ is the point of phase space, $m$ is the embedding dimension, $N$ is the number of phase points in the reconstructed phase space, and $t_{N}=t_{n}-(m-1) \tau$.

The specific steps of the $G-P$ algorithm are as follows.

Suppose that there are some phase points in $m$-dimensional phase space:

$$
\begin{aligned}
& X_{b}=\left\{x\left(t_{b}\right), x\left(t_{b}+\tau\right), \ldots, x\left(t_{b}+(m-1) \tau\right)\right\}, \\
& X_{e}=\left\{x\left(t_{e}\right), x\left(t_{e}+\tau\right), \ldots, x\left(t_{e}+(m-1) \tau\right)\right\} .
\end{aligned}
$$

In the above equation, $b, e=1,2, \ldots, N$ and $|b-e|>\tau$. The distance between the pair points is recorded as $d_{b e}=\left\|X_{b}-X_{e}\right\|$. Given a distance value of $r$, the $G-P$ algorithm checks how many pairs of points $\left(X_{b}, X_{e}\right)$ have a distance $d_{b e}<r$ among the $N$ points embedding in the phase space and marks the proportion of the pairs whose distance is less than $r$ in all pairs as correlation function $C(r)$, which indicates how many state points are interrelated, that is, the density of phase points in the phase space, which reflects the correlation degree and regularity degree of system motion.

$$
C(r)=\frac{1}{N^{2}} \sum_{b=1}^{N} \sum_{e=1}^{N} \theta\left(r-\left\|X_{b}-X_{e}\right\|\right) \text {. }
$$

From the above equation, $\theta(x)=\left\{\begin{array}{ll}1 & x=\left(r-\left\|X_{b}-X_{e}\right\|\right)>0, \\ 0 & x=\left(r-\left\|X_{b}-X_{e}\right\|\right)<0 .\end{array}\right.$ is Heaviside function. 
The fractal dimension of RADV index is $D=\lim _{r \rightarrow 0}(\ln C(r) / \ln r)$, which is the correlation dimension. In the actual calculation process, for different embedding dimension $m$, there is a corresponding $D$, which can be marked as $D(m)$. For RADV index, when $m$ increases to $m_{c}, D(m)$ will no longer change significantly with $m$ and become saturated; then the embedding dimension $m_{c}$ is the saturation embedding dimension. $D(m)$ and $m_{c}$ are the lower and upper number limits of main factors associated with the RADV index, respectively.

\subsection{Identifying the Main Influencing Factors}

2.2.1. Constructing a Collection of RADV Influencing Factors. To identify the main influencing factors of RADV, the paper first constructs a collection of influencing factors as the basis of factor selection. RADV is mainly affected by both sensitivity and recovery factors. Sensitivity refers to the sum of the factors that exacerbate the drought hazards in agriculture; that is, the more sensitive the agricultural system, the greater the drought vulnerability of the agricultural system. Recovery refers to the sum of the various favorable factors to mitigate the harm of agricultural drought; that is, the more restorative the agricultural system, the weaker the drought vulnerability of the agricultural system. Considering that the RADV is the result of the joint action of natural environmental and socioeconomic systems [32], by excluding uncontrollable factors, with the principles of scientificity, integrity, and data availability, the influencing factors in existing studies are summarized, and a collection of RADV influencing factors is initially constructed from both sensitivity and recovery, as shown in Table 1.

\subsubsection{Ranking the Importance of Influencing Factors Based on} TGRA Method. The paper holds that the perspective of the absolute and relative amount of data changes can not only make full use of data information but also reflect the trend of data change more comprehensively. Therefore, based on the absolute and relative amount of data changes, the trend change is defined, and the grey trend relational coefficient is given by the composition ratio and difference of the trend change amount, and the symbol function is introduced to reflect the positive and negative correlations between the time sequences; then the TGRA method is proposed, which can rank the influencing factors according to the grey trend relational degree.

Definition 2. Suppose that the time sequence on interval $[f, g]$ is $X_{\phi}=\left\{x_{\phi}\left(t_{1}\right), x_{\phi}\left(t_{2}\right), \ldots, x_{\phi}\left(t_{n}\right)\right\}, \quad(\phi=0,1,2$, $\ldots, l)$; then

$$
\begin{aligned}
x_{\phi}\left(\Delta t_{k}\right) & =x_{\phi}\left(t_{k}\right)-x_{\phi}\left(t_{k-1}\right), \\
D_{\phi} & =\frac{\sum_{k=2}^{n}\left|x_{\phi}\left(\Delta t_{k}\right)\right|}{n-1}, \\
x_{\phi}^{\prime}\left(\Delta t_{k}\right) & =\frac{x_{\phi}\left(t_{k}\right)-x_{\phi}\left(t_{k-1}\right)}{\left|x_{\phi}\left(t_{k-1}\right)\right|}, \\
D_{\phi}^{\prime} & =\frac{\sum_{k=2}^{n}\left|x_{\phi}^{\prime}\left(\Delta t_{k}\right)\right|}{n-1}, \\
z_{\phi}\left(\Delta t_{k}\right) & =\alpha \cdot \frac{x_{\phi}\left(\Delta t_{k}\right)}{D_{\phi}}+\beta \cdot \frac{x_{\phi}^{\prime}\left(\Delta t_{k}\right)}{D_{\phi}^{\prime}},
\end{aligned}
$$

respectively, represent the absolute amount of data change, mean of absolute amount of data change, relative amount of data change, mean of relative amount of data change, and the trend amount of data change of time sequences $X_{\phi}$ from point of time $t_{k-1}$ to point of time $t_{k}$.

In the above equation, $\Delta t_{k}=t_{k}-t_{k-1}, \quad[f, g]=$ $\cup_{k=2}^{n} \Delta t_{k}, \Delta t_{k} \cap \Delta t_{k-} 1=\varnothing, g>f \geq 0, k=2,3, \ldots, n ; \alpha$ and $\beta$ represent the emphasis on the absolute and relative amount of data changes, respectively, and $\alpha+\beta=1$.

Definition 3. Suppose that the RADV index on interval $[f, g]$ is $X_{0}=\left\{x_{0}\left(t_{1}\right), x_{0}\left(t_{2}\right), \ldots, x_{0}\left(t_{n}\right)\right\}$; the influencing factor is $X_{i}=\left\{x_{i}\left(t_{1}\right), x_{i}\left(t_{2}\right), \ldots, x_{i}\left(t_{n}\right)\right\} \quad(i=1,2, \ldots, u)$; then

$$
\xi_{0 i}^{t_{k}}= \begin{cases}\operatorname{sgn}\left(z_{0}\left(\Delta t_{k}\right) \cdot z_{i}\left(\Delta t_{k}\right)\right) \cdot \frac{1}{1+(1 / 2)|| z_{0}\left(\Delta t_{k}\right)|-| z_{i}\left(\Delta t_{k}\right)||+(1 / 2)\left[1-\left(\left(\min \left(\left|z_{0}\left(\Delta t_{k}\right)\right|,\left|z_{i}\left(\Delta t_{k}\right)\right|\right)\right) /\left(\max \left(\left|z_{0}\left(\Delta t_{k}\right)\right|,\left|z_{i}\left(\Delta t_{k}\right)\right|\right)\right)\right)\right],} & \text { others, } \\ 1, & z_{0}\left(\Delta t_{k}\right)=z_{i}\left(\Delta t_{k}\right)=0,\end{cases}
$$

is the grey trend relational coefficient between the RADV index $X_{0}$ and the influencing factor $X_{i}$ from the point of time $t_{k-1}$ to point of time $t_{k}$.

In the above equation, $\operatorname{sgn}\left(z_{0}\left(\Delta t_{k}\right) \cdot z_{i}\left(\Delta t_{k}\right)\right)$ is a symbolic function used to reflect the positive and negative correlations between the RADV index $X_{0}$ and the influencing factor $X_{i}$. When $z_{0}\left(\Delta t_{k}\right) \cdot z_{i}\left(\Delta t_{k}\right) \geq 0, \operatorname{sgn}\left(z_{0}\left(\Delta t_{k}\right) \cdot z_{i}\right.$
$\left.\left(\Delta t_{k}\right)\right)=1$, and $\xi_{0 i}^{t_{k}}>0$, which indicates that $X_{0}$ and $X_{i}$ change in the same direction during the period from the point of time $t_{k-1}$ to the point of time $t_{k}$, that is, positive correlation. When $z_{0}\left(\Delta t_{k}\right) \cdot z_{i}\left(\Delta t_{k}\right)<0, \quad \operatorname{sgn}\left(z_{0}\left(\Delta t_{k}\right) \cdot z_{i} \quad\left(\Delta t_{k}\right)\right)=-1, \quad$ and $\xi_{0 i}^{t_{k}}<0$, which indicates that $X_{0}$ and $X_{i}$ change in the opposite direction during the period from the point of time $t_{k-1}$ to the point of time $t_{k}$, that is, negative correlation. 
TABLE 1: A collection of RADV influencing factors.

\begin{tabular}{|c|c|c|c|c|}
\hline $\begin{array}{l}\text { Guideline } \\
\text { layer }\end{array}$ & Influencing factors & $\begin{array}{l}\text { Influencing } \\
\text { directions }\end{array}$ & Influencing factors & $\begin{array}{c}\text { Influencing } \\
\text { directions }\end{array}$ \\
\hline \multirow{10}{*}{ Sensitivity } & $\begin{array}{c}\text { Water consumption per } 10000 \text { yuan GDP } \\
\text { of agricultural }\left(X_{1}\right)\end{array}$ & + & $\begin{array}{l}\text { Proportion of agricultural output value } \\
\qquad\left(X_{2}\right)\end{array}$ & + \\
\hline & $\begin{array}{c}\text { Water consumption per unit value added } \\
\text { of agriculture }\left(X_{3}\right)\end{array}$ & + & $\begin{array}{l}\text { Total agricultural water consumption } \\
\qquad\left(X_{4}\right)\end{array}$ & + \\
\hline & $\begin{array}{c}\text { Per capita living water consumption of } \\
\text { rural residents }\left(X_{5}\right)\end{array}$ & + & Per capita water resources $\left(X_{6}\right)$ & - \\
\hline & $\begin{array}{l}\text { Average water consumption per mu of } \\
\text { farmland irrigation }\left(X_{7}\right)\end{array}$ & + & Multiple-crop index $\left(X_{8}\right)$ & + \\
\hline & Cover rate of forest $\left(X_{9}\right)$ & - & Proportion of watered land area $\left(X_{10}\right)$ & + \\
\hline & Population density $\left(X_{11}\right)$ & + & $\begin{array}{l}\text { Proportion of agricultural population } \\
\qquad\left(X_{12}\right)\end{array}$ & + \\
\hline & Per capita arable land area $\left(X_{13}\right)$ & - & Proportion of grain planting area $\left(X_{14}\right)$ & + \\
\hline & Proportion of water field area $\left(X_{15}\right)$ & + & $\begin{array}{c}\text { Proportion of autumn grain crop } \\
\text { planting area }\left(X_{16}\right)\end{array}$ & + \\
\hline & Proportion of corn planting area $\left(X_{17}\right)$ & + & $\begin{array}{l}\text { Proportion of summer grain crop } \\
\text { planting area }\left(X_{18}\right)\end{array}$ & + \\
\hline & Proportion of rice planting area $\left(X_{19}\right)$ & + & $\begin{array}{l}\text { Proportion of wheat planting area } \\
\left(X_{20}\right)\end{array}$ & + \\
\hline \multirow{11}{*}{ Recovery } & $\begin{array}{c}\text { Per capita disposable income of rural } \\
\text { households }\left(X_{21}\right)\end{array}$ & - & Per capita fiscal income $\left(X_{22}\right)$ & - \\
\hline & Per capita GDP $\left(X_{23}\right)$ & - & Intensity of R\&D funding $\left(X_{24}\right)$ & - \\
\hline & Consumption level of rural residents $\left(X_{25}\right)$ & - & Number of rural labor resources $\left(X_{26}\right)$ & - \\
\hline & Rural electricity consumption $\left(X_{27}\right)$ & - & $\begin{array}{c}\text { Total power of agricultural machinery } \\
\text { per unit area }\left(X_{28}\right)\end{array}$ & - \\
\hline & $\begin{array}{l}\text { Pure amount of fertilizer application per } \\
\text { unit area }\left(X_{29}\right)\end{array}$ & - & Use of plastic film per unit area $\left(X_{30}\right)$ & - \\
\hline & $\begin{array}{c}\text { Mechanical harvest area of agricultural } \\
\text { year }\left(X_{31}\right)\end{array}$ & - & Waterlogging control area $\left(X_{32}\right)$ & - \\
\hline & Soil erosion control area $\left(X_{33}\right)$ & - & $\begin{array}{c}\text { Proportion of water-saving irrigation } \\
\text { area }\left(X_{34}\right)\end{array}$ & - \\
\hline & Total reservoir capacity $\left(X_{35}\right)$ & - & Per capita grain yield $\left(X_{36}\right)$ & - \\
\hline & Grain unit area yield $\left(X_{37}\right)$ & - & Corn unit area yield $\left(X_{38}\right)$ & - \\
\hline & Wheat unit area yield $\left(X_{39}\right)$ & - & Rice unit area yield $\left(X_{40}\right)$ & - \\
\hline & Summer grain unit area yield $\left(X_{41}\right)$ & - & Autumn grain unit area yield $\left(X_{42}\right)$ & - \\
\hline
\end{tabular}

Definition 4. Suppose that the RADV index on interval $[f, g]$ is $X_{0}=\left\{x_{0}\left(t_{1}\right), x_{0}\left(t_{2}\right), \ldots, x_{0}\left(t_{n}\right)\right\}$; the influencing factor is $X_{i}=\left\{x_{i}\left(t_{1}\right), x_{i}\left(t_{1}\right), \ldots, x_{i}\left(t_{n}\right)\right\}(i=1,2, \ldots, u)$; then,

$$
\gamma_{0 i}=\frac{1}{b-a} \sum_{k=2}^{n} \Delta t_{k} \cdot \xi_{0 i}^{t_{k}},
$$

is the trend grey relational degree between the RADV index $X_{0}$ and the influencing factor $X_{i}$.

When $-1 \leq \gamma_{0 i}<0, X_{0}$ is negatively correlated with $X_{i}$, and the larger $\left|\gamma_{0 i}\right|$, the stronger the negative correlation. When $0<\gamma_{0 i} \leq 0, X_{0}$ is positively correlated with $X_{i}$, and the larger $\left|\gamma_{0 i}\right|$, the stronger the positive correlation. When $\left|\gamma_{0 i}\right|=0, X_{0}$ is not related to $X_{i}$.

Theorem 1. The grey trend relational degree $\gamma_{0 i}$ has the following properties:
(1) Normativity. $\left|\gamma_{0 i}\right| \leq 1$; when $x_{0}\left(t_{k}\right)=\lambda x_{i}\left(t_{k}\right), \lambda$ is a nonzero constant, and $\left|\gamma_{0 i}\right|=1$ is established.

(2) Symmetry. $\gamma\left(X_{0}, X_{i}\right)=\gamma\left(X_{i}, X_{0}\right)$.

(3) Proximity. The closer sequences $X_{0}$ and $X_{i}$ are, the larger $\left|\gamma_{0 i}\right|$ is.

(4) Uniqueness and comparability.

(5) Isotony. After dimensionless processing such as initialization in the same direction, multiplication, averaging, and percentage, the grey trend relational degree is not changed, so the sequence does not produce ordinal effects.

Proof. (1) Normativity. If $x_{0}\left(t_{k}\right)=\lambda x_{i}\left(t_{k}\right), \lambda$ is a nonzero constant; then

$$
x_{0}\left(\Delta t_{k}\right)=x_{0}\left(t_{k}\right)-x_{0}\left(t_{k-1}\right)=\lambda x_{i}\left(t_{k}\right)-\lambda x_{i}\left(t_{k-1}\right)=\lambda x_{i}\left(\Delta t_{k}\right),
$$




$$
\begin{aligned}
x_{0}^{\prime}\left(\Delta t_{k}\right)= & \frac{x_{0}\left(t_{k}\right)-x_{0}\left(t_{k-1}\right)}{\left|x_{0}\left(t_{k-1}\right)\right|}= \begin{cases}\frac{\lambda x_{i}\left(t_{k}\right)-\lambda x_{i}\left(t_{k-1}\right)}{\left|\lambda x_{i}\left(t_{k-1}\right)\right|}=x_{i}^{\prime}\left(\Delta t_{k}\right), & \lambda>0, \\
\frac{\lambda x_{i}\left(t_{k}\right)-\lambda x_{i}\left(t_{k-1}\right)}{\left|\lambda x_{i}\left(t_{k-1}\right)\right|}=-x_{i}^{\prime}\left(\Delta t_{k}\right), & \lambda<0,\end{cases} \\
D_{0}= & \begin{cases}\frac{\sum_{k=2}^{n}\left|x_{0}\left(\Delta t_{k}\right)\right|}{n-1}=\frac{\sum_{k=2}^{n}\left|\lambda x_{i}\left(\Delta t_{k}\right)\right|}{n-1}=\lambda D_{i}, \quad \lambda>0, \\
\frac{\sum_{k=2}^{n}\left|x_{0}\left(\Delta t_{k}\right)\right|}{n-1}=\frac{\sum_{k=2}^{n}\left|\lambda x_{i}\left(\Delta t_{k}\right)\right|}{n-1}=-\lambda D_{i}, & \lambda<0,\end{cases} \\
D_{0}^{\prime}= & \frac{\sum_{k=2}^{n}\left|x_{0}^{\prime}\left(\Delta t_{k}\right)\right|}{n-1}=\frac{\sum_{k=2}^{n}\left|x_{i}^{\prime}\left(\Delta t_{k}\right)\right|}{n-1}=D_{i}^{\prime}, \\
z_{0}\left(\Delta t_{k}\right)= & \alpha \cdot \frac{x_{0}\left(\Delta t_{k}\right)}{D_{0}}+\beta \cdot \frac{x_{0}^{\prime}\left(\Delta t_{k}\right)}{D_{0}^{\prime}}= \begin{cases}\alpha \cdot \frac{\lambda x_{i}\left(\Delta t_{k}\right)}{\lambda D_{i}}+\beta \cdot \frac{x_{i}^{\prime}\left(\Delta t_{k}\right)}{D_{i}^{\prime}}=z_{i}\left(\Delta t_{k}\right), & \lambda>0, \\
\alpha \cdot \frac{\lambda x_{i}\left(\Delta t_{k}\right)}{-\lambda D_{i}}+\beta \cdot \frac{x_{i}^{\prime}\left(\Delta t_{k}\right)}{-D_{i}^{\prime}}=-z_{i}\left(\Delta t_{k}\right), & \lambda<0,\end{cases}
\end{aligned}
$$

and therefore and then

$$
\begin{aligned}
\left|z_{0}\left(\Delta t_{k}\right)\right|-\left|z_{i}\left(\Delta t_{k}\right)\right| & =1-\frac{\min \left(\left|z_{0}\left(\Delta t_{k}\right)\right|,\left|z_{i}\left(\Delta t_{k}\right)\right|\right)}{\max \left(\left|z_{0}\left(\Delta t_{k}\right)\right|,\left|z_{i}\left(\Delta t_{k}\right)\right|\right)}=0, \\
\operatorname{sgn}\left(z_{0}\left(\Delta t_{k}\right) \cdot z_{i}\left(\Delta t_{k}\right)\right) & = \begin{cases}1, & \lambda>0, \\
-1, & \lambda<0,\end{cases}
\end{aligned}
$$

$$
\gamma_{0 i}=\left\{\frac{1}{b-a} \sum_{k=2}^{n} \Delta t_{k} \cdot 1=1, \lambda>0, \frac{1}{b-a} \sum_{k=2}^{n} \Delta t_{k} \cdot(-1)=-1, \lambda<0 .\right.
$$

Namely, $\left|\gamma_{0 i}\right|=1$.

From the derivation of formulas (6) and (7), it can be seen that the properties in (2)-(6) are obviously valid.
(5) Isotony. Taking the same direction initialization as an example, sequences $X_{0}$ and $X_{i}$ are normalized, and the normalized sequences are noted as $X_{0}^{\Delta}$ and $X_{i}^{\Delta}$; then

$$
\begin{aligned}
x_{0}^{\Delta}\left(t_{k}\right) & =\frac{x_{0}\left(t_{k}\right)}{x_{0}\left(t_{1}\right)} \\
x_{0}^{\Delta}\left(t_{k-1}\right) & =\frac{x_{0}\left(t_{k-1}\right)}{x_{0}\left(t_{1}\right)} \\
x_{0}^{\Delta}\left(\Delta t_{k}\right) & =x_{0}^{\Delta}\left(t_{k}\right)-x_{0}^{\Delta}\left(t_{k-1}\right)=\frac{x_{0}\left(t_{k}\right)}{x_{0}\left(t_{1}\right)}-\frac{x_{0}\left(t_{k-1}\right)}{x_{0}\left(t_{1}\right)}=\frac{x_{0}\left(\Delta t_{k}\right)}{x_{0}\left(t_{1}\right)}, \\
x_{0}^{\Delta}\left(\Delta t_{k}\right) & =x_{0}^{\Delta}\left(t_{k}\right)-x_{0}^{\Delta}\left(t_{k-1}\right)=\frac{x_{0}\left(t_{k}\right)}{x_{0}\left(t_{1}\right)}-\frac{x_{0}\left(t_{k-1}\right)}{x_{0}\left(t_{1}\right)}=\frac{x_{0}\left(\Delta t_{k}\right)}{x_{0}\left(t_{1}\right)},
\end{aligned}
$$




$$
\begin{aligned}
x_{0}^{\prime \Delta}\left(\Delta t_{k}\right) & =\frac{x_{0}^{\Delta}\left(t_{k}\right)-x_{0}^{\Delta}\left(t_{k-1}\right)}{\left|x_{0}^{\Delta}\left(t_{k-1}\right)\right|}=\frac{\left(x_{0}\left(t_{k}\right)-x_{0}\left(t_{k-1}\right)\right) \cdot\left|x_{0}\left(t_{1}\right)\right|}{x_{0}\left(t_{1}\right) \cdot\left|x_{0}\left(t_{k-1}\right)\right|}= \begin{cases}x_{0}^{\prime}\left(\Delta t_{k}\right), & x_{0}\left(t_{1}\right)>0, \\
-x_{0}^{\prime}\left(\Delta t_{k}\right), & x_{0}\left(t_{1}\right)<0,\end{cases} \\
D_{0}^{\Delta} & =\frac{\sum_{k=2}^{n}\left|x_{0}^{\Delta}\left(\Delta t_{k}\right)\right|}{n-1}=\frac{\sum_{k=2}^{n}\left|x_{0}\left(\Delta t_{k}\right)\right|}{(n-1) \cdot\left|x_{0}\left(t_{1}\right)\right|}= \begin{cases}\frac{D_{0}}{x_{0}\left(t_{1}\right)}, & x_{0}\left(t_{1}\right)>0, \\
-\frac{D_{0}}{x_{0}\left(t_{1}\right)}, & x_{0}\left(t_{1}\right)<0,\end{cases} \\
D_{0}^{\prime \Delta}= & \frac{\sum_{k=2}^{n}\left|x_{0}^{\prime \Delta}\left(\Delta t_{k}\right)\right|}{n-1}=\frac{\sum_{k=2}^{n}\left|x_{0}^{\prime}\left(\Delta t_{k}\right)\right|}{(n-1)}=D_{0}^{\prime},
\end{aligned}
$$

and therefore

$$
z_{0}^{\Delta}\left(\Delta t_{k}\right)=\alpha \cdot \frac{x_{0}^{\Delta}\left(\Delta t_{k}\right)}{D_{0}^{\Delta}}+\beta \cdot \frac{x_{0}^{\prime \Delta}\left(\Delta t_{k}\right)}{D_{0}^{\prime \Delta}}= \begin{cases}\alpha \cdot \frac{x_{0}\left(\Delta t_{k}\right) \cdot x_{0}\left(t_{1}\right)}{x_{0}\left(t_{1}\right) \cdot D_{0}}+\beta \cdot \frac{x_{0}^{\prime}\left(\Delta t_{k}\right)}{D_{0}^{\prime}}=z_{0}\left(\Delta t_{k}\right), & x_{0}\left(t_{1}\right)>0, \\ \alpha \cdot \frac{x_{0}\left(\Delta t_{k}\right) \cdot x_{0}\left(t_{1}\right)}{-x_{0}\left(t_{1}\right) \cdot D_{0}}+\beta \cdot \frac{-x_{0}^{\prime}\left(\Delta t_{k}\right)}{D_{0}^{\prime}}=-z_{0}\left(\Delta t_{k}\right), & x_{0}\left(t_{1}\right)<0\end{cases}
$$

Similarly,

$$
\begin{aligned}
& x_{i}^{\Delta}\left(\Delta t_{k}\right)=\frac{x_{i}\left(\Delta t_{k}\right)}{x_{i}\left(t_{1}\right)} \\
& x_{i}^{\prime \Delta}\left(\Delta t_{k}\right)= \begin{cases}x_{i}^{\prime}\left(\Delta t_{k}\right), & x_{i}\left(t_{1}\right)>0 \\
-x_{i}^{\prime}\left(\Delta t_{k}\right), & x_{i}\left(t_{1}\right)<0\end{cases} \\
& D_{i}^{\Delta}= \begin{cases}\frac{D_{i}}{x_{i}\left(t_{1}\right)}, & x_{i}\left(t_{1}\right)>0, \\
-\frac{D_{i}}{x_{i}\left(t_{1}\right)}, & x_{i}\left(t_{1}\right)<0,\end{cases} \\
& D_{i}^{\prime \Delta}=D_{i}^{\prime}, \\
& z_{i}^{\Delta}\left(\Delta t_{k}\right)= \begin{cases}z_{i}\left(\Delta t_{k}\right), & x_{i}\left(t_{1}\right)>0 \\
-z_{i}\left(\Delta t_{k}\right), & x_{i}\left(t_{1}\right)<0\end{cases} \\
& \operatorname{sgn}\left(z_{0}^{\Delta}\left(\Delta t_{k}\right) \cdot z_{i}^{\Delta}\left(\Delta t_{k}\right)\right)= \begin{cases}\operatorname{sgn}\left(z_{0}\left(\Delta t_{k}\right) \cdot z_{i}\left(\Delta t_{k}\right)\right)=1, & x_{0}\left(t_{1}\right)>0, x_{i}\left(t_{1}\right)<0, \\
\operatorname{sgn}\left(-z_{0}\left(\Delta t_{k}\right) \cdot\left(-z_{i}\left(\Delta t_{k}\right)\right)\right)=1, & x_{0}\left(t_{1}\right)>0, x_{i}\left(t_{1}\right)<0,\end{cases} \\
& || z_{i}^{\Delta}\left(\Delta t_{k}\right)|-| z_{j}^{\Delta}\left(\Delta t_{k}\right)||=|| z_{i}\left(\Delta t_{k}\right)|-| z_{i}\left(\Delta t_{k}\right)||, \\
& \frac{\min \left(\left|z_{i}^{\Delta}\left(\Delta t_{k}\right)\right|,\left|z_{j}^{\Delta}\left(\Delta t_{k}\right)\right|\right)}{\max \left(\left|z_{i}^{\Delta}\left(\Delta t_{k}\right)\right|,\left|z_{j}^{\Delta}\left(\Delta t_{k}\right)\right|\right)}=\frac{\min \left(\left|z_{i}\left(\Delta t_{k}\right)\right|,\left|z_{j}\left(\Delta t_{k}\right)\right|\right)}{\max \left(\left|z_{i}\left(\Delta t_{k}\right)\right|,\left|z_{j}\left(\Delta t_{k}\right)\right|\right)} \text {. }
\end{aligned}
$$


Therefore, after the initialization in the same direction, the grey trend relational coefficient is unchanged, the same as the grey trend relational degree. Similarly, it can be proved that the dimensionless processing such as multiplication in the same direction, averaging, and percentage does not change the grey trend relational degree.

\subsubsection{Clustering the Influencing Factors Based on TGRC} Method. Depending on the grey trend relational degree between the RADV index $X_{0}$ and the influencing factor sequence $X_{i}$, the importance of the influencing factors can be ranked, but the main influencing factors cannot be filtered entirely according to the degree of importance, since some influencing factors may fall into the same category, which will not only increase the redundancy of data collection but also reduce the comprehensiveness of the factor screening. Therefore, it is necessary to cluster the influencing factors and merge the similar factors. TGRC is a method that is based on TGRA, constructing grey trend correlation matrix of the influencing factors and clustering the influencing factors by selecting appropriate relational threshold.

Definition 5. Assume that there are influencing factor sequences $X_{i}=\left\{x_{i}\left(t_{1}\right), x_{i}\left(t_{2}\right), \ldots, x_{i}\left(t_{n}\right)\right\} \quad$ and $X_{j}=\left\{x_{j}\left(t_{1}\right), x_{j}\left(t_{2}\right), \ldots, x_{j}\left(t_{n}\right)\right\}$ on interval $[f, g]$. For all $i \leq j, i=1,2, \ldots, u$, according to formulas (4) and (6), the grey trend relational degree between $X_{i}$ and $X_{j}$ is calculated, and the upper triangular matrix is obtained:

$$
Y=\left[\begin{array}{cccc}
\gamma_{11} & \gamma_{12} & \ldots & \gamma_{1 u} \\
& \gamma_{22} & \ldots & \gamma_{2 u} \\
& & \ddots & \vdots \\
& & & \gamma_{u u}
\end{array}\right],
$$

is the grey trend relational matrix of the influencing factors.

From the above equation, $\gamma_{i i}=1$, and the relational threshold takes $r \in[0,1]$, which can be set according to the needs of the actual problem. When $\left|\gamma_{i j}\right| \geq r, X_{i}$ and $X_{j}$ are treated as the same influencing factors, and they are grouped into the same category. If $\left|\gamma_{i h}\right| \geq r$ appears at the same time and $h=1,2, \ldots, u$, but $i \neq j \neq h$, TGRC takes the smallest influencing factor of $X_{i}, X_{j}, X_{h}$ in the label $i, j, h$ as the representative of each category and combines the other two influencing factors into one with the smallest label to become a category. By traversing the whole grey trend correlation matrix, according to the relational threshold, the clustering results can be obtained, and the similar influencing factors merged.

\section{Identification Results and Analysis}

Henan Province is located in the center of the Huang-HuaiHai Plain, which is a typical grain export province in China. However, due to the influence of the monsoon climate, drought occurs frequently, posing a huge threat to food security [33], and the research on drought issues needs to be strengthened urgently. In this paper, Henan Province is selected as the research object; the main influencing factors of RADV are identified by the PSR-TGRC method to reduce the degree of RADV and provide theoretical support for reducing agricultural drought losses.

3.1. Data Sources. In this paper, the annual precipitation comes from the China Meteorological Data Network from 1960 to 1998, and the annual precipitation comes from the Henan Provincial Water Resources Bulletin from 1999 to 2018, containing 19 typical meteorological stations in Henan Province (Anyang, Xinxiang, Zhengzhou, Nanyang, Xinyang, etc.). The data of the remaining factors mainly comes from the China Statistical Yearbook, the China Rural Statistical Yearbook, the China Science and Technology Statistical Yearbook, and the Henan Provincial Statistical Yearbook from 2012 to 2018.

\subsection{Identification Results}

3.2.1. The Number of Main Influencing Factors of RADV in Henan Province. In order to identify the number of influencing factors of RADV in Henan Province, the PSR method is used to reconstruct the RADV index and calculate the RADV index of Henan Province from 1960 to 2018 according to formula (1), as shown in Figure 2.

After using the SPSS software to calculate the delay time of the RADV index in Henan Province, it is found that the autocorrelation function value of the RADV index changes with the delay time $\tau$, as shown in Figure 3. It can be seen from the figure that when $\tau=3$, the autocorrelation function value is -0.036 and it is approximately 0 for the first time, so the delay time of the RADV index in Henan Province is 3.

Taking the RADV index sequence from 1960 to 2018 in Henan Province as the object of PSR, the $G-P$ algorithm is realized by MATLAB R2018b. By analyzing the change characteristics of the correlation dimension and the embedding dimension, the number of factors affecting RADV in Henan Province is explored. The relationship between embedding dimension and correlation dimension is shown in Figure 4.

It can be found from Figure 4 that when the embedding dimension $m=14$, the correlation dimension $D(m)$ reaches a saturation value of 4.36 , which indicates that the RADV index of Henan Province is a chaotic time sequence, and the number of variables required to describe the chaotic sequence is 5 to 14 ; that is, when evaluating the degree of RADV, 5 to 14 main influencing factors must be selected for the evaluation. The result is basically consistent with the number of factors affecting RADV in the existing literatures $[3,9,10]$.

\subsubsection{The Main Influencing Factors of RADV in Henan} Province. The main influencing factors of Henan Province from 2012 to 2018 are identified based on TGRA and TGRC; the former is to identify the main influencing factors, and the latter is to identify the influence trend of factors on RADV. The RADV index of Henan Province from 2012 to 2018 showed an overall increasing trend (as shown in Figure 2). If 


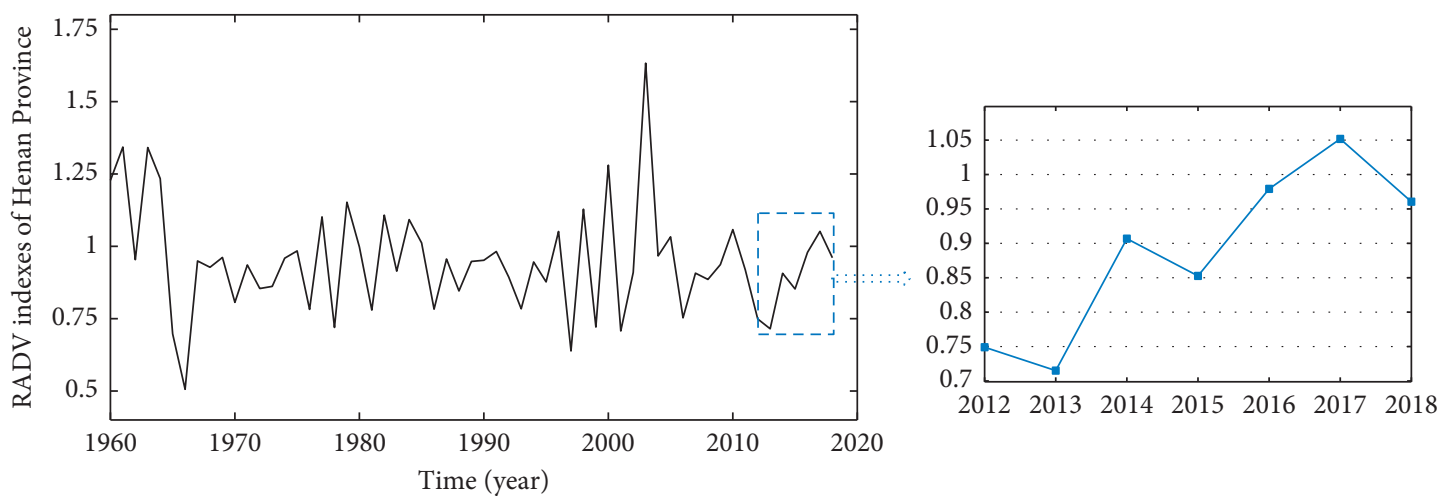

Figure 2: RADV index in Henan Province.

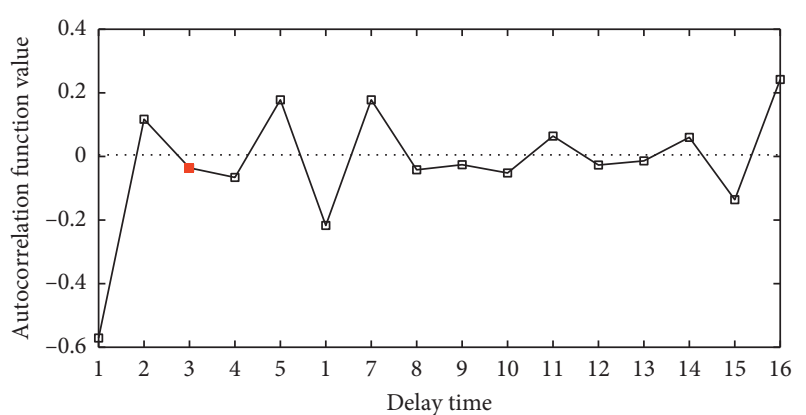

FIgURE 3: The curve of autocorrelation function with delay time.

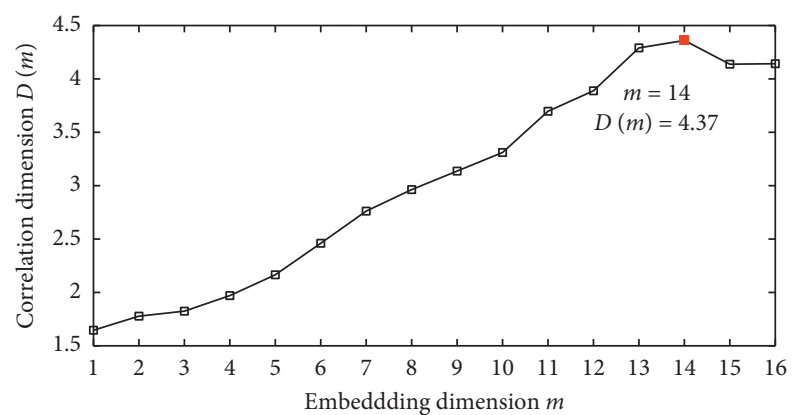

FIGURE 4: The relationship between embedding dimension $m$ and correlation dimension $D(m)$.

the influencing factors on RADV of Henan Province have the same direction as the grey trend relational degree, the development trend of influencing factors has a positive effect on the increase of RADV in Henan Province, and it is denoted as $X^{+}$. If the influencing factors on the RADV of Henan Province have the opposite direction as the grey trend relational degree, the development trend of influencing factors has a negative effect on the increase of RADV in Henan Province, and it is denoted as $X^{-}$.

According to formulas (6) and (7), the grey trend relational degree between the 42 factors in Table 1 and the RADV index in Henan Province were calculated, in which $\alpha=\beta=0.5$. According to formula (14), 20 influencing factors of sensitivity level and 22 influencing factors of recovery level were analyzed by grey trend relational clustering.

In this paper, taking 14 influencing factors as examples, since they can more comprehensively represent the factors needed in the evaluation of RADV in Henan Province, the main influencing factors are screened out. According to the principle of comprehensiveness, the numbers of selected sensitivity factors and recovery factors should be balanced as far as possible, and they are clustered into 7 categories, respectively, to determine the clustering threshold and the main influencing factors. Taking sensitivity factors as an example, the grey trend relational degrees between 20 sensitivity factors and the RADV index are calculated according to formulas (6) and (7) and combined with the influencing direction of sensitivity factors of RADV and the direction of sensitivity factors on the development trend of RADV. The importances of influencing factors in Henan Province are ranked as follows:

$$
X_{6}^{-}>X_{17}^{+}>X_{5}^{-}>X_{7}^{-}>X_{13}^{+}>X_{15}^{+}>X_{9}^{-}>X_{4}^{-}>X_{18}^{+}>X_{19}^{+}>X_{2}^{-}>X_{14}^{-}>X_{16}^{-}>X_{10}^{+}>X_{2}^{-}>X_{3}^{+}>X_{11}^{-}>X_{12}^{+}>X_{20}^{+}>X_{8}^{-}
$$

A clustering analysis of 20 sensitivity factors is performed according to Definition 5, and the clustering results between the 20 sensitivity factors at different thresholds are shown in Table 2.

According to the clustering of sensitivity factors under different thresholds, when threshold $r$ selects 0.5166 , the sensitivity factors can be divided into 7 categories, and the main sensitivity factors can be identified by combining the ranking results of 20 sensitivity factors. The identification results can be found in Table 3. The recovery factors and the identification process of sensitivity factors are similar, so the detailed process will not be listed in this paper.

3.3. Results Analysis. During the period from 2012 to 2018, the main influencing factors of sensitivity in order of importance are per capita water resources $\left(X_{6}\right)$, the proportion of corn planting area $\left(X_{17}\right)$, per capita living water 
TABLE 2: Clustering results of sensitivity factors of RADV in Henan Province.

\begin{tabular}{lr}
\hline Threshold $r$ & Clustering results \\
\hline 0.8362 & $\left\{X_{1}, X_{3}\right\},\left\{X_{11}, X_{12}\right\}$ \\
0.6823 & $\left\{X_{1}, X_{3}\right\},\left\{X_{11}, X_{12}\right\},\left\{X_{14}, X_{18}, X_{20}\right\}$ \\
0.6313 & $\left\{X_{1}, X_{3}\right\},\left\{X_{2}, X_{13}\right\},\left\{X_{4}, X_{7}\right\},\left\{X_{11}, X_{12}\right\},\left\{X_{14}, X_{18}, X_{20}\right\}$ \\
0.6069 & $\left\{X_{1}, X_{3}\right\},\left\{X_{2}, X_{13}\right\},\left\{X_{4}, X_{7}\right\},\left\{X_{5}, X_{19}\right\},\left\{X_{10}, X_{14}, X_{18}, X_{20}\right\},\left\{X_{11}, X_{12}\right\}$ \\
0.5843 & $\left\{X_{1}, X_{3}\right\},\left\{X_{2}, X_{11}, X_{12}, X_{13}\right\},\left\{X_{4}, X_{7}\right\},\left\{X_{5}, X_{19}\right\},\left\{X_{10}, X_{14}, X_{18}, X_{20}\right\}$ \\
0.5593 & $\left\{X_{1}, X_{3}\right\},\left\{X_{2}, X_{11}, X_{12}, X_{13}\right\},\left\{X_{4}, X_{7}\right\},\left\{X_{5}, X_{10}, X_{14}, X_{18}, X_{19}, X_{20}\right\}$ \\
0.5269 & $\left\{X_{1}, X_{3}, X_{4}, X_{7}\right\},\left\{X_{2}, X_{11}, X_{12}, X_{13}\right\},\left\{X_{5}, X_{10} X_{14}, X_{18}, X_{19}, X_{20}\right\}$ \\
0.5166 & $\left\{X_{1}, X_{3}, X_{4}, X_{7}\right\},\left\{X_{2}, X_{8}, X_{11}, X_{12}, X_{13}\right\},\left\{X_{5}, X_{10} X_{14}, X_{16}, X_{18}, X_{19}, X_{20}\right\}$ \\
0.5153 & $\left\{X_{1}, X_{2}, X_{3}, X_{4}, X_{7}, X_{8}, X_{11}, X_{12}, X_{13}\right\},\left\{X_{5}, X_{10} X_{14}, X_{16}, X_{18}, X_{19}, X_{20}\right\}$ \\
0.5131 & $\left\{X_{1}, X_{2}, X_{3}, X_{4}, X_{7}, X_{8}, X_{10}, X_{11}, X_{12}, X_{13}, X_{14}, X_{16}, X_{18}, X_{19}, X_{20}\right\}$ \\
0.4793 & $\left\{X_{1}, X_{2}, X_{3}, X_{4}, X_{7}, X_{8}, X_{10}, X_{11}, X_{12}, X_{13}, X_{14}, X_{15}, X_{16}, X_{17}, X_{18}, X_{19}, X_{20}\right\}$ \\
0.4411 & $\left\{X_{1}, X_{2}, X_{3}, X_{4}, X_{5}, X_{6}, X_{7}, X_{8}, X_{10}, X_{11}, X_{12}, X_{13}, X_{14}, X_{15}, X_{16}, X_{17}, X_{18}, X_{19}, X_{20}\right\}$ \\
\hline
\end{tabular}

TABLE 3: The identification results of main influencing factors of RADV in Henan Province.

Calculation method

Identification results

Guideline layer

Sensitivity factors

Grey trend relational analysis

Grey $T$-type relational analysis

Grey rate of change relational analysis

Grey comprehensive relational analysis

$X_{6}^{-}, X_{17}^{+}, X_{5}^{-}, X_{7}^{-}, X_{13}^{+}, X_{11}^{+}, X_{9}^{-}$
$X_{6}^{-}, X_{17}^{+}, X_{13}^{+}, X_{5}^{-}, X_{15}^{+}, X_{9}^{-}, X_{12}^{+}$
$X_{6}^{-}, X_{17}^{+}, X_{18}^{+}, X_{7}^{-}, X_{9}^{-}, X_{2}^{-}, X_{15}^{+}$
$X_{1}, X_{2}, X_{4}, X_{6}, X_{19}, X_{17}, X_{8}$

Recovery factors

$X_{36}^{+}, X_{29}^{+}, X_{40}^{-}, X_{42}^{+}, X_{31}^{+}, X_{33}^{-}, X_{30}^{-}$

$X_{36}^{+}, X_{29}^{+}, X_{40}^{-}, X_{38}^{+}, X_{31}^{+}, X_{37}^{+}, X_{33}^{-}$

$X_{28}^{+}, X_{38}^{+}, X_{29}^{+}, X_{40}^{-}, X_{33}^{-}, X_{25}^{-}, X_{35}^{+}$

$X_{23}, X_{31}, X_{33}, X_{22}, X_{21}, X_{27}, X_{28}$ consumption of rural residents $\left(X_{5}\right)$, average water consumption per mu of farmland irrigation $\left(X_{7}\right)$, per capita arable land area $\left(X_{13}\right)$, the proportion of water field area $\left(X_{15}\right)$, and cover rate of forest $\left(X_{9}\right)$. The main influencing factors of recovery in order of importance are per capita grain yield $\left(X_{36}\right)$, pure amount of fertilizer application per unit area $\left(X_{29}\right)$, rice unit area yield $\left(X_{40}\right)$, autumn grain unit area yield $\left(X_{42}\right)$, mechanical harvest area of agricultural year $\left(X_{31}\right)$, soil erosion control area $\left(X_{33}\right)$, and use of plastic film per unit area $\left(X_{30}\right)$. In general, the influencing factors of RADV in Henan Province are mainly related to natural resources, agricultural industrial structure, agricultural attention, agricultural water efficiency, residents' awareness of water conservation, water and soil conservation measures, and so forth, and the identification results are consistent with the actual drought relief work in Henan Province [34].

The increasing trend of the proportion of corn planting area $\left(X_{17}\right)$ and the proportion of water field area $\left(X_{15}\right)$, as well as the increase of per capita arable land area $\left(X_{13}\right)$, per capita grain yield $\left(X_{36}\right)$, pure amount of fertilizer application per unit area $\left(X_{29}\right)$, and autumn grain unit area yield $\left(X_{42}\right)$, and the decreasing trend of mechanical harvest area of agricultural year $\left(X_{31}\right)$ are the main influencing factors driving the increase of RADV in Henan Province. Therefore, we should focus on adjusting the trend of these factors in order to reduce the RADV in Henan Province.

In addition, per capita water resources $\left(X_{6}\right)$, cover rate of forest $\left(X_{9}\right)$, rice unit area yield $\left(X_{40}\right)$, soil erosion control area $\left(X_{33}\right)$, and use of plastic film per unit area $\left(X_{30}\right)$, as well as the per capita living water consumption of rural residents $\left(X_{5}\right)$, and the reduction of the average water consumption per mu of farmland irrigation $\left(X_{7}\right)$ are the main influencing factors to inhibit the increase of RADV in Henan Province.
It is shown that the development trend of these influencing factors is better, which has not yet caused threat to the increase of RADV in Henan Province; and, based on affirming the preliminary work, the above influencing factors should continue to be controlled to prevent their evolution from causing disaster.

3.4. Comparative Analysis. The grey T-type relational analysis [28], the grey rate of change relational analysis [29], and the grey comprehensive relational analysis [26] are used to perform relational clustering analysis to compare the identification results of influencing factors. The specific results (ranked by the importance of influencing factors) are shown in Table 3.

There are some differences in the influencing factors of RADV in Henan Province obtained by different grey relational analysis methods. The first three kinds of grey relational analysis methods can distinguish the influence trend of factors on the degree of RADV in Henan Province from 2012 to 2018, and the difference in the identification results of factors is small, in which the ranking result of grey trend relational analysis method adjusts the different ranking of grey $T$-type relational analysis method and grey rate of change relational analysis method, while the grey comprehensive relational analysis method is quite different from the first three grey relational analysis methods.

There are two main reasons for the above differences:

(1) The aspect of structure selection of relational analysis method. The first three grey relational analysis methods take the perspective of data composition ratio and composition difference to define the correlation degree, while the grey comprehensive 
relational analysis method takes the perspective of data composition difference to define the correlation degree.

(2) The aspect of data selection. The grey $T$-type relational analysis method and the grey rate of change relational analysis method select the absolute and relative amount of data in each period, respectively, while the grey comprehensive relational analysis method selects the absolute and relative amount between data points and ignores the amount of change in the development of data.

In this paper, the grey trend relational analysis method integrates the idea of grey comprehensive relational analysis method on data selection, and the dynamic development characteristics of the RADV index and the influencing factors are fully considered. The trend change is defined by selecting the absolute and relative amount of data changes in each period, and correlation degree between the RADV index and the influencing factors is measured. Therefore, it will be more comprehensive and objective to examine the correlation of the RADV index and the influencing factors by using the grey trend relational analysis method.

\section{Managerial Implications}

According to the above main influencing factors driving or inhibiting the increase of RADV in Henan Province, the corresponding managerial implications are put forward to reduce the RADV in Henan Province.

For the main factors driving the increase of RADV in Henan Province, the specific measures are as follows:

(1) Optimizing the planting structure of crops, reducing production according to market changes, selecting drought-tolerant crop varieties, and making full use of rainfall and irrigation water to reduce the yield losses of crops caused by water shortage.

(2) Actively protecting arable land, strictly controlling the conversion of arable land to nonarable land, and increasing effective arable land area to improve land quality and utilization efficiency.

(3) Increasing the amount of farm manure and decreasing phosphorus-containing chemical fertilizer applied in land to promote agricultural production to avoid destroying the ecological balance.

(4) Giving full play to the supporting and guiding role of agricultural machinery purchase subsidies and other policy projects, focusing on improving the level of agricultural mechanization, improving agricultural production efficiency, and promoting farmers' income to improve the ability of drought resistance and disaster prevention by developing modern agriculture.

For the main factors inhibiting the increase of RADV in Henan Province, the specific measures are as follows:

(1) Strengthening the publicity of drought and water conservation and guiding enterprises and the masses to raise awareness of drought and water conservation to increase the utilization rate of water resources.

(2) Increasing forest cover area and greening efforts, optimizing tree species and forest structure, improving forest quality, and strengthening the construction of large areas of forest corridors, such as wetland parks and other forest ecological spaces between Zhengzhou, the provincial capital, and surrounding cities.

(3) Strengthening the construction, maintenance, and management of farmland water conservancy infrastructure, improving agricultural irrigation technology, and the reuse rate of industrial water to reduce the loss of water resources.

(4) Paying attention to the integration of soil erosion control with the local pillar industries, the people's poverty alleviation, and the adjustment of industrial structure and increasing the construction of water and soil conservation measures such as slope conversion, small-scale water conservancy, and water storage projects, water conservation forests, and economic forests.

(5) Increasing the promotion of high-quality agricultural film, improving the efficiency of agricultural film use from the perspectives of screening the best uncovering period of crops, and strengthening the drought management of seedlings to minimize the losses caused by drought.

\section{Conclusions}

As for the influencing factor identification of RADV, a PSRTGRC method is proposed. From the aspects of sensitivity and recovery, 42 influencing factors are selected to construct a collection of RADV influencing factors. Using the method of PSR in chaos theory, the number of influencing factors of RADV is quantitatively analyzed. Then, considering the absolute and relative amount of data changes in each period, the grey trend relational analysis method and the grey trend relational clustering analysis method are proposed. The PSRTGRC method is applied to identify the influencing factors of RADV in Henan Province, while three other grey relational analysis methods are selected for comparative analysis, which verifies the effectiveness and superiority of PSRTGRC method. Finally, combined with the main influencing factors and effects of RADV in Henan Province in 2012-2018, the corresponding measures are put forward.

In this paper, the province is chosen as the research unit, and the PSR-TGRC method is used to identify the influencing factors of RADV, which can provide a reference for the selection of influencing factors in the subsequent evaluation process. Next, in the evaluation and study, the research areas should be refined and the differences of agricultural drought problems within regions should be deeply analyzed. In addition, this paper gives more consideration to human factors but less consideration to natural factors, such as topography, soil vegetation, and other factors on the formation of agricultural drought and postdisaster 
recovery. The collection of RADV influencing factors can be updated with the improvement of data.

\section{Data Availability}

The data used to support the findings of this study are available from the corresponding author upon request.

\section{Conflicts of Interest}

The authors declare that there are no conflicts of interest regarding the publication of this paper.

\section{Acknowledgments}

This research was supported by the doctoral innovation fund project of North China University of Water Resources and Electric Power.

\section{References}

[1] Q. Zhang, Y.-B. Yao, Y.-H. Li et al., "Progress and prospect on the study of causes and variation regularity of droughts in China," Acta Meteorologica Sinica, vol. 78, no. 3, pp. 500-521, 2020.

[2] Z.-H. Hu, Z.-R. Wu, A. R. M. T. Islam et al., "spatiotemporal characteristics and risk assessment of agricultural drought disasters during the winter wheat-growing season on the Huang-Huai-Hai plain, China," Theoretical and Applied Climatology, vol. 143, no. 3-4, pp. 1-15, 2021.

[3] L. Xu and W.-C. Zhang, "Assessment of regional agricultural drought vulnerability and main influencing factors," $A d$ vances in Science and Technology of Water Resources, vol. 38, no. 2, pp. 14-19+43, 2018.

[4] J. Wu, G. Geng, H. Zhou, J. Liu, Q. Wang, and J. Yang, "Global vulnerability to agricultural drought and its spatial characteristics," Science China Earth Sciences, vol. 60, no. 5, pp. 910-920, 2017.

[5] D. Wu, D.-H. Yan, G.-Y. Yang, X.-G. Wang, W.-H. Xiao, and H.-T. Zhang, "Assessment on agricultural drought vulnerability in the Yellow River basin based on a fuzzy clustering iterative model," Natural Hazards, vol. 67, no. 2, pp. 919-936, 2013.

[6] J.-Z. Xie, S.-F. Che, and Y. Lin, "Vulnerability assessment and the driving force in the management of agricultural drought hazard," Journal of Southwest University (Social Science Edition), vol. 43, pp. 43-53+189-190, 2017.

[7] S. M. Kim, M. S. Kang, and M. W. Jang, "Assessment of agricultural drought vulnerability to climate change at a municipal level in South Korea," Paddy and Water Environment, vol. 16, no. 4, pp. 699-714, 2018.

[8] J.-L. Jin, H.-Y. Zhang, M.-L. Chen et al., "Evaluation of regional agricultural drought vulnerability coupled with dynamic connection number and full partial certainty," Journal of Beijing Normal University (Natural Science), vol. 55, no. 6, pp. 724-730, 2019.

[9] L.-F. Liu, X. Guan, and Y.-S. Tang, "Vulnerability of agricultural drought and agricultural losses reduction during drought through implementation of ecological measures-—a case study of Hengyang, Hu'nan Province," Bulletin of Soil and Water Conservation, vol. 5, no. 2, pp. 69-73, 2005.

[10] G.-Q. Jiang, G.-L. Yu, and Y. Zhao, "An analysis of vulnerability to agricultural drought in China using the expand grey relation analysis method," Procedia Engineering, vol. 28, pp. 670-676, 2012.

[11] J.-L. Jin, H.-Y. Zhang, M.-L. Chen et al., "Evaluation and diagnosis of agricultural drought vulnerability based on grey correlation and connection number coupling," Journal of Catastrophology, vol. 34, no. 1, pp. 1-7, 2019.

[12] R.-S. Huang, Chaos and its Application, Press of Wuhan University, Wuhan, China, 2000.

[13] D. I. H. Abarbanel, Analysis of Observed Chaotic Data, Press of Springer, New York City, NY, USA, 1996.

[14] W.-D. Chen and P.-L. Gu, "Phase space reconstruction and the analysis of its chaos," Journal of TianJin University, vol. 35, no. 3, pp. 293-297, 2002.

[15] L.-Y. Zhou, "Study on the time-series fractal characteristics of being effected area of drought disaster in Guangdong at the last fifty year," Territory \& Natural Resources Study, vol. 27, no. 3, pp. 34-36, 2005.

[16] S.-Q. Xu, G.-X. Zhou, H.-M. Yu et al., "Grey correlation analysis on impact factors of agricultural machinery total power," Agricultural Mechanization Research, vol. 38, no. 12, pp. 56-60+65, 2016.

[17] E. Simelton, E. D. G. Fraser, M. Termansen, P. M. Forster, and A. J. Dougill, "Typologies of crop-drought vulnerability: an empirical analysis of the socio-economic factors that influence the sensitivity and resilience to drought of three major food crops in China (1961-2001)," Environmental Science \& Policy, vol. 12, no. 4, pp. 438-452, 2009.

[18] F.-F. Zhao, B. He, X.-H. Li et al., "Assessment of reginal agricultural drought vulnerability and identification of main influencing factors: a case study in Henan and Hebei Province," Journal of Beijing Normal University (Natural Science), vol. 48, no. 3, pp. 282-286, 2012.

[19] T.-T. Yang, X.-H. Wu, P. Li et al., "Construction of the vulnerability evaluation index system for climate change in steppe area of northern China," Journal of Arid Land Resources and Environment, vol. 26, no. 1, pp. 115-118, 2012.

[20] Z.-W. Zhu, J. Shi, and Y.-Y. Liu, "The risk assessment and key risk factor identification in the view of public policy process," Chinese Public Administration, vol. 22, no. 7, pp. 102-109, 2015.

[21] N. Sun, Z. Zhao, and W.-L. Wang, "Study on the evaluation of forestry sustainable development in Weibei area of the Loess Plateau," Agricultural Research in the Arid Area, vol. 30, no. 6, pp. 215-220, 2012.

[22] C.-H. Li, Z. Qiao, J. Dai et al., "Identification of key factors of new product development projects based on ANP," Modern Management Science, vol. 17, no. 7, pp. 15-18, 2013.

[23] J.-Q. Ma and X. Wei, "Drought evaluation index system based on the fuzzy comprehensive evaluation and its application in north China," Journal of Anhui Agricultural Science, vol. 38, no. 19, pp. 10138-10140, 2010.

[24] B. He, Q.-J. Wang, D. Wu et al., “Agricultural drought risk assessment in Shaanxi province using principal component analysis and AHP," Agricultural Research in the Arid Areas, vol. 35, no. 1, pp. 219-227, 2017.

[25] Q. Cui, C.-Y. Wu, and H.-B. Kuang, "Influencing factors research of airports competitiveness based BP-DEMATEL model," Systems Engineering-Theory and Practice, vol. 33, no. 6, pp. 1471-1478, 2013.

[26] S.-F. Liu, Y.-J. Yang, and L.-F. Wu, Grey Systems: Theory and Applications, Press of Science, Beijing, China, 2014.

[27] W.-X. Tang, "The concept and computation method of Ts correlation degree," Application of Statistics and Management, vol. 14, no. 1, pp. 34-37+33, 1995. 
[28] Y.-G. Sun and Y.-G. Dang, "Improvement on grey T's correlation degree," System Engineering-Theory \& Practice, vol. 28, no. 4, pp. 135-139, 2008.

[29] X.-M. Li, Y.-G. Dang, and L. Jin, “Trend analysis based on grey relational degree with rate of change and its application," Chinese Journal of Management Science, vol. 23, no. 9, pp. 132-138, 2015.

[30] Y. F. Ma, P. F. Niu, and X. F. Ma, "Research on the phase space reconstruction method of chaotic time series," Applied Mechanics and Materials, vol. 26-28, pp. 236-240, 2010.

[31] M. Chen, D.-Z. Xu, and Q.-Y. Luo, "Research on phase space reconstruction of time series and its application," Journal of Computer Science and Technology, vol. 13, no. 11, pp. 7-8, 2005.

[32] W. Pei, Q. Fu, D. Liu, T.-X. Li, and K. Cheng, "Assessing agricultural drought vulnerability in the Sanjiang Plain based on an improved projection pursuit model," Natural Hazards, vol. 82, no. 1, pp. 683-701, 2016.

[33] Z.-G. Li, Z.-F. Guo, Y.-W. Zhang et al., "Spatial-temporal characteristics of crop drought in Henan for recent 36 years," Journal of Arid Land Resources and Environment, vol. 29, no. 4, pp. 119-124, 2015.

[34] K. Peng, L. Ye, and P.-S. Hou, "2019 Henan provincial water conservancy work conference held," Henan Water Conservancy and South-to-North Water Diversion, vol. 48, no. 1, p. 4, 2019. 